\title{
Supervisão pedagógica de professores na Universidade Pedagógica de Moçambique: averiguando opiniões
}

\begin{abstract}
Maria José Rodrigues ${ }^{a}$, Cristina Martins ${ }^{b}$, Dario Santos ${ }^{c}$, Lubacha Zilhão ${ }^{d}$, Rogério Almoço ${ }^{\mathrm{e}}$

${ }^{a}$ Centro de Investigação em Educação Básica, Instituto Politécnico de Bragança, Bragança, Portugal,

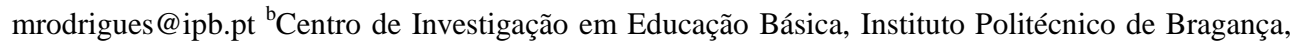
Bragança, Portugal, mcesm@ipb.pt 'Dário Santos, Universidade Pedagógica de Moçambique, Manica, Moçambique, darionhungue18@gmail.com ${ }^{\mathrm{d}}$ Lubacha Zilhão, Universidade Pedagógica de Moçambique, Manica, Moçambique, lubachazilhao@gmail.com ${ }^{\mathrm{e}}$ Rogério Almoço Universidade Pedagógica de Moçambique, Manica, Moçambique, rogerioalmoco@gmail.com
\end{abstract}

\section{Resumo}

Cientes que a supervisão pedagógica é um processo fundamental para o desenvolvimento profissional dos professores e futuros professors, surge a realização do estudo que envolve investigadores da Escola Superior de Educação do Instituto Politécnico de Bragança (ESE-IPB) e a Universidade Pedagógica de Moçambique - delegação de Manica (UP - Manica). Numa fase inicial, pretendemos conhecer a opinião dos supervisores da UP Manica acerca do processo de supervisão pedagógica. Trata-se de uma invetigação qualitativa, de natureza descritiva e interpretativa. O inquérito surge, nesta fase, como a técnica de recolha de dados principal, sendo um questionário constituído por questões abertas e fechadas, o instrumento utilizado. Neste, foi solicitado aos participantes a caraterização do processo de supervisão. Dos 16 supervisores que responderam, houve unanimidade na resposta no que concerne ao destaque que atribuem à importância deste processo, nomeadamente na formação dos alunos - futuros professores - $e$, particulramente, na sua integração nas escolas. Muito embora seja clara uma associação do processo à avaliação dos alunos, para a caraterização do processo descrevem atividades que desenvolvem, tal como o acompanhamento dos alunos na planificação e observação de aulas. Quando identificam os constrangimentos que sentem, o número excessivo de alunos, a dispersão geográfica das escolas e o tempo de que dispõem para realizar a supervisão, são os aspetos mais registados. Enumeram como sugestão para a melhoria do processo a formação dos supervisores, o número de alunos por supervisor e os recursos materiais. Desta feita, concluímos que é imperativo otimizar a qualidade do processo de supervisão pedagógica, o que cremos 
seja facilitado, conforme perpstivamos, pela cooperação estabelecida entre parceiros e instituições..

Palavras-chave: formação de professores, desenvolvimento profissional, supervisão pedagógica,

\section{Contextualização da investigação}

O projeto em curso partiu dos interesses comuns de investigação de um grupo de professores/as do ensino superior, de dois países lusófonos. Neste, temos como objetivo principal idealizar um programa de formação contínua com e para os professores supervisores. Em termos teóricos situamos a nossa investigação no âmbito do desenvolvimento profissional de professores, especificamente numa das formas de o promover - a formação contínua de professores - e, especificamente, na supervisão pedagógica da formação inicial de professores.

É nosso entendimento e conforme sublinhamos numa publicação anterior (Marins, et al, 2019), que na formação inicial e contínua de professores, o processo de supervisão assume particular importância, dado que propicia o desenvolvimento profissional do futuro professor ou do professor em exercício. Este pressupõe a articulação de diferentes atores para a criação de um ambiente formativo em que a colaboração, a partilha de saberes e ideias, a interação, o apoio, a experimentação e a reflexão estão presentes. No processo de supervisão ressalvamos o papel do supervisor, como agente de mudança, facilitador e encorajador, numa escola em constante mudança e repleta de desafios. Para tal é necessário, pois, que analise, desenvolva, renove e atualize constantemente as suas competências, encarando a formação contínua numa perspetiva de desenvolvimento profissional e de aprendizagem ao longo da vida. Sendo que o sujeito fundamental do seu próprio desenvolvimento professional é o professor/supervisor, conhecer as perceções dos supervisores sobre o processo em que estão envolvidos é um ponto privilegiado no nossa investigação. Reafirmando e conforme perspetivado desde o ínicio, a ideia de criação de um programa de formação contínua com e para supervisores, que deverá partir das suas necessidades e expectativas, além de que o desenvolvimento profissional produz melhores resultados quando se organiza durante um período alargado de tempo, é centrado no trabalho colaborativo, na prática, na reflexão e valoriza a investigação (Marins, et al, 2019). 


\section{Abordagem metodológica}

A investigação em curso é de natureza qualitativa e interpretativa (Bogdan \& Biklen, 1994). Pretendemos reunir um conjunto de informação pertinente com a finalidade de a interpretarmos.

Nesta fase do estudo - averiguação das perceções dos professores/supervisores sobre o processo de supervisão - utlizámos o questionário, como técnica de recolha de dados. Neste contexto, consideramos que a formação continuada dos docentes deve assumir um papel decisivo e ir ao encontro das reais necessidades de formação dos intervenientes (Rodrigues e Vieira, 2018) e o professor deverá ter um papel ativo no seu próprio desenvolvimento professional (Pires e Martins, 2010). O referido instrumento era constituído por 5 questões, com várias alíneas, organizadas em três secções: (i) caraterização pessoal; (ii) formação e experiência profissional; e (iii) Processo de supervisão no UPM - DM. Neste artigo, damos ênfase à secção Processo de supervisão no UPM - DM. Para o tratamento dos dados recolhidos através de questões fechadas recorremos à estatística descritiva. No respeitante às questões abertas, a informação foi sujeita a análise de conteúdo. Para o efeito, fizemos uma leitura prévia de todas as respostas, e criámos categorias de acordo com os aspetos mais relevantes de cada questão. Como refere Bardin (1995) a análise de conteúdo "aparece como um conjunto de técnicas de análise das comunicações, que utiliza procedimentos sistemáticos e objetivos de descrição do conteúdo das mensagens” (p. 38). Genericamente, as etapas de realização da análise de conteúdo são sequencialmente a descrição, a inferência e a interpretação (Carmo \& Ferreira, 1998).

No que respeita aos participantes nesta fase do estudo - averiguação das perceções responderam 16 supervisores, sendo 14 do sexo masculino e 2 do sexo feminino, destes, 10 têm entre vinte e cinco a trinta e cinco anos e 6 têm entre trinta e seis e quarenta e cinco. Relativamente à sua formação inicial, 6 são licenciados e 10 têm o grau de mestrado. Grande parte (8) assinal que tem de percorrer entre dez a vinte quilómetros desde a sua residência até ao local onde realizam a supervisão. Dada a variedade de formações existentes na UPM-DM, as áreas de formação dos supervisores são muito diversas, bem como realizam a supervisão em áreas muito distintas. No que respeita à sua experiência profissional, verifica-se que têm entre 2 a 15 anos de serviço enquanto professores e entre 2 a 9 anos de experiência em supervisão. Globalmente, verificamos, que o número de anos de serviço é superior ao número de anos que desempenham o papel de supervisores. 

opiniões

\section{Processo de supervisão: resultados}

Na primeira questão deste grupo "caraterize o processo de supervisão na UP - Manica", três docentes não responderam e dois apresentaram respostas que não consideramos válidas, pois não respondiam ao que se questionava. Assim, das onze respostas obtidas, sete fazem referência às atividades desenvolvidas durante o processo supervisivo, nomeadamente, a distribuição dos estagiários, a planificação do trabalho e a observação de aulas, tal como é evidenciado nos seguintes excertos:

O processo de supervisão na UP - Manica segue as linhas orientadoras constantes nos documentos normativos da UP, nomeadamente, o calendário académico, regulamento académico, plano curricular. No curso de ensino da Biologia, por exemplo, todos os docentes participam na supervisão/estágio pedagógico, orientando estudantes nas atividades inerentes à cadeira (S2)

O docente é alocado a um estudante em uma escola; o docente corrige os planos de aula antes de ser submetido à aula; o supervisor assiste à aula e avalia a aula (S5)

Os docentes supervisores têm que assistir pelo menos 5 aulas dos estudantes. Na escola o estudante trabalha com o tutor (professor da turma) durante no mínimo 10 semanas. Existe uma última aula em que o supervisor vai assistir para avaliação (S12).

Como é evidente nos discursos de S5 e S12 o processo de supervisão surge associado à avaliação dos estagiários. Esta mesma opinião é partilhada por S11 quando refere que "depois da distribuição dos alunos (DC) tem o momento de socialização dos horários, assiste-se às aulas onde é classificado o estudante mediante o seu desempenho. A classificação do estudante associa-se à avaliação do professor acompanhante".

De salientar ainda que as respostas de alguns supervisores parecem referir a supervisão como um processo que decorre de uma forma agradável, como o S8 que menciona "ocorre de uma forma harmoniosa" e S13 "é organizado e tem fases distintas e sequenciadas", no entanto outras parecem transparecer alguma preocupação. S7 escreve "tem sido uma atividade árdua, visto que o efetivo de docentes é insuficiente para o número de estudantes, e as escolas estão relativamente dispersas". Esta opinião é partilhada por outros, sendo o número de estudantes que têm de acompanhar o aspeto mais referenciado e que, na opinião de alguns supervisores, pode comprometer a supervisão. Esta ideia é claramente expressa nos seguintes discursos:

Complexo e insuficiente. O supervisor não consegue supervisionar todos os estudantes com a qualidade que se espera (S6, S13).

Tenho constatado na maior parte dos cursos a falta de acompanhamento dos estudantes por parte dos docentes (supervisores) e consequentemente, o desempenho do aluno é muito baixo (S10) 
Pelas respostas apresentadas verificamos que os supervisores não partilham a mesma opinião relativamente ao processo de supervisão, enquanto para uns é entendido como um processo organizado e até agradável, outros apontam as suas fragilidades e as principais dificuldades que, na sua opinião, caraterizam o referido processo.

No que respeita ao papel que os supervisores atribuem ao processo de supervisão para a formação de professores, três optaram por não responder e uma das respostas não a consideramos válida. Assim, das doze respostas analisadas sobressai o papel atribuído à supervisão enquanto processo de formação dos estudantes, visível na maior parte dos discursos:

auxilia o aluno no seu desenvolvimento no processo de formação (S1)

a supervisão em processos pedagógicos tem um papel central na formação de professores na medida em que garante a dinâmica e qualidade das atividades relacionadas com a formação, permite detetar e corrigir os erros/falhas cometidos, entre outros (S2)

Importante, pois possibilita auxiliar e ajudar os demais para que tenham uma formação de qualidade (S4)

Permite que o professor verifique se os seus formandos fazem a ligação entre a teoria e a prática; permite melhorar o conhecimento aprendido (S6)

Dar aos estudantes conhecimentos práticos e metodológicos no processo de ensino e aprendizagem; familiarizar no estudante o futuro meio que estará inserido no seu dia a dia" (S8)

O processo de supervisão para o professor tem um papel fundamental na concretização e alcance dos objetivos preconizados" (S9)

Fundamental na formação integral do professor(S13)

Alguns supervisores relevam o acompanhamento dos estudantes e a relevância do mesmo para o seu desenvolvimento, a este respeito S5 refere "[o processo supervisivo é] mediador entre o conhecimento adquirido e o transmissor", na mesma linha S7 acrescenta que "[a supervisão dá] orientações para a melhoria da qualidade da prática na área da docência/educação". Os discursos de S10 e S12 reforçam esta ideia quando mencionam, respetivamente, que "o acompanhamento do aluno durante o período da supervisão é muito fundamental visto que é a partir desse processo que o aluno poderá reduzir ou eliminar algumas lacunas que foi observando durante as práticas" (S 10) e "a supervisão se for bem feita é muito importante porque ajuda o aluno a melhorar profissionalmente, é o supervisor que vai lhe aconselhar sobre o que está bem e o que está mal na sua atuação como professor de forma a melhorar" (S 12). Já S14 destaca o papel do supervisor, indicando que o mesmo tem a responsabilidade de "verificar os planos de aula antes de ser dada a aula; assistir à aula do estudante praticante; avaliar cada aula assistida junto com o tutor local", mais uma vez a supervisão surge associada à avaliação do estudante. 

opiniões

Nas respostas analisadas surgem, com menor frequência, outros aspetos relacionados com a supervisão, como por exemplo permitir a aproximação entre a universidade e a escola integrada, referido por $\mathrm{S} 1$, e promover a articulação entre vários saberes e a iniciação à pesquisa mencionado por $\mathrm{S} 13$.

Os supervisores, quando questionados sobre as fragilidades e os constrangimentos que sentem no desenvolvimento do processo de supervisão, apontam para os aspetos apresentados na tabela 1 .

Tabela 1. Fragilidades/constrangimentos

\begin{tabular}{|l|c|}
\hline Fragilidades/constrangimentos & N. $^{\mathbf{0}}$ de respostas \\
\hline Escassez de tempo do supervisor e do estágio & 8 \\
\hline Elevado número de estudantes por supervisor & 5 \\
\hline Ausência de transporte & 4 \\
\hline Falta de comunicação entre a UP e a escola/tutor local & 4 \\
\hline Fraca logística (liderança, pagamento) & 3 \\
\hline Papel do tutor local & 3 \\
\hline Distância do local de estágio & 2 \\
\hline Falta de recursos & 2 \\
\hline Falta de conhecimentos das atividades supervisivas & 1 \\
\hline
\end{tabular}

Verificamos que 8 supervisores indicam a escassez de tempo como constrangimento do processo supervisivo. Esta ideia é clarificada nos seguintes discursos:

O não acompanhamento do estudante praticante do estágio num semestre (o estágio começa no meio de um semestre e não termina todo o semestre) (S5)

Muitas das vezes os alunos são colocados nas escolas fora do período estabelecido para o efeito. O aluno não tem muito tempo para realização do estágio/práticas (S10)

Falta de tempo para supervisionar visto que o docente tem que dar aulas a outras turmas no período em que o supervisando está a dar aulas; falta de comprometimento de alguns supervisores e tutores que deixam o estudante a estagiar sozinho (S12)

Pouco número de aulas para poder ser avaliado; o praticante apenas dá aulas na escola por um período curto e não há continuidade das atividades na mesma escola (S14)

Por outro lado, importa referir que esta opinião já tinha sido expressa pelos supervisores quando lhes solicitamos para caraterizar o processo de supervisão. Do discurso de S2 sobressaem outras preocupações que se prendem- com o número de estagiários por supervisor com a falta de transporte "a distância entre o local do estágio da supervisão em 
relação ao de residência ou local de trabalho do docente; elevado número de estudantes por docente".

Por último, destacamos que alguns supervisores demonstram algum descontentamento relativamente às interações com as escolas que recebem os estagiários e o seu respetivo acompanhamento, tal como evidencia a opinião de S8 "Recusa de algumas instituições (privadas) em receber os estudantes; abandono dos estudantes por parte do tutor local”.

Em articulação com a questão anterior solicitamos aos supervisores que indicassem sugestões para melhorar o processo de supervisão, as suas respostas estão expressas na tabela 2 .

Tabela 2. Sugestões

\begin{tabular}{|l|c|}
\hline Sugestões & N. ${ }^{\circ}$ de respostas \\
\hline Formação dos supervisores & 4 \\
\hline Gestão do tempo & 4 \\
\hline Redução do n. ${ }^{\text {o de estagiários por supervisor }}$ & 4 \\
\hline Organização do processo & 4 \\
\hline Realização de seminários entre a UP e as escolas & 2 \\
\hline Troca de experiências & 2 \\
\hline Disponibilidade de recursos e transporte & 2 \\
\hline
\end{tabular}

São várias as sugestões que os supervisores indicam, designadamente, um maior investimento na sua formação, apontam a formação continua como uma mais-valia para exercerem o papel de supervisores e também a patilha de experiências com outros docentes, como refere S2 “capacitação/troca de experiências em matéria de supervisão de processos pedagógicos, tais como: supervisão pedagógica, supervisão do estágio pedagógico e de práticas profissionalizantes e de práticas pedagógicas”.

Em concordância com os constrangimentos que enumeraram propõem mais tempo para a realização do estágio e para a permanência do estagiários nas escolas e a redução do número de estagiários por supervisor, a este respeito S12 sugere "que houvesse docentes que só se dedicassem ao estágio no semestre em que este ocorre; que o estudante ficasse pelo menos 6 meses no estágio".

Sugerem, ainda, a organização mais eficaz do processo, como evidencia o discurso de S 10 quando refere ser fundamental "Preparar o expediente para colocação dos alunos com muita antecedência; os supervisores devem participar em todas as fases práticas nas escolas; e dar o parecer aos alunos de todas as aulas assistidas". 

opiniões

\section{Sinopse conclusiva}

Os resultados apresentados demonstram que os supervisores atribuem importância ao processo de supervisão na formação inicial de professores, destacando a sua relevância do ponto de vista formativo, uma vez que, na sua opinião, contribui para o processo de ensinoaprendizagem e para o desenvolvimento profissional dos estudantes. Valorizam o acompanhamento que fazem dos estagiários, evidenciando o papel de cada um dos intervenientes no processo. É evidente nos discursos descritos que a supervisão surge associada à avaliação dos estudantes, o que nos leva a inferir que, de certa forma, os supervisores a valorizam do ponto de vista formativo, mas também a encaram como um processo regulador.

Apontam algumas dificuldades associadas à supervisão, quer do ponto de vista organizacional, quer da disponibilidade de recursos que têm à disposição. Sendo a supervisão um processo complexo, dinâmico e multidimensional implica a articulação entre todos os agentes envolvidos e a mobilização de recursos, o que em determinados momentos se pode constituir como um constrangimento ao seu desenvolvimento. No entanto, e no sentido de dar resposta aos problemas identificados elencam um conjunto de propostas para os minimizar. Entendem a formação continua como fundamental, quer do ponto de vista concetual quer do ponto de vista didático-pedagógico. Sugerem também uma gestão mais eficaz dos recursos e a promoção de interações mais positivas entre a universidade e as escolas de acolhimento dos estagiários.

\section{Referências}

Bardin, L. (1995). Análise de conteúdo. Lisboa: Edições 70.

Bogdan, R., \& Biklen, S. (1994). Investigação qualitativa em educação - Uma introdução à teoria e aos métodos. Porto: Porto Editora.

Martins, C., Rodrigues, M. J., Santos, D., Zilhão, L. \& Almoço, R. (2019). Supervisão pedagógica numa instituição de ensino superior moçambicana: averiguando perceções. In Pires, M. V., Mesquita, C., Lopes, R. P., Silva, E., \& Patrício, M. R. (Eds.) (2019). Livro de atas do IV Encontro Internacional de Formação na Docência (INCTE 2019). Bragança, Portugal: Instituto Politécnico de Bragança (no prelo).

Pires, M. V., \& Martins, C. (2010). Formação e desenvolvimento profissional do professor de Matemática. In Gomes H.; Menezes, L.; Cabrita, I. (orgs.) Actas do XXI Seminário de Investigação em Educação Matemática. Aveiro: Associação de Professores de Matemática. p. 414-424.

Rodrigues, M. J.; Vieira, R. M. (2018). Formação continuada para a mudança de práticas didáticopedagógicas de educadoras. In Lopes, Rui Pedro; Castanheira, Manuel Luís Pinto; Silva, Elisabete; Sousa, G.; Sousa, J.; Pires, Manuel Pires; Mesquita, Cristina (Eds.) III Encontro Internacional de Formação na Docência (INCTE): Livro de Resumos. Bragança. 